\title{
Halka Açılmada Sermaye Artırımı Yoluyla Satışa Hazır Bekletilen Payların Satışının Pay Getirilerine Etkileri
}

\author{
Arif SEZGIN* $\quad$ Sinan AYTEKINN**
}

\begin{abstract}
$\ddot{O} Z$
Bu çalışmanın amacı, ilk halka arz sonrasında sermaye artırımı yoluyla satışa hazır bekletilen payların satışının pay getirileri üzerindeki etkilerinin araştııılmasıdır. Çalışmanın kapsamını 2013-2020 yılları arasında satışa hazır bekletilen pay satışı yapan BIST şirketleri oluşturmaktadır. Olay etüdü yönteminin kullanıldığı çalışmada, olay günü olarak satışa hazır bekletilen payların satış tarihi belirlenmiştir. Olay penceresi olarak ise olay gününden 5 gün öncesi ve sonrast $(-/+5)$ incelenmiştir. Payların beklenen getirilerinin hesaplanmasında Sermaye Varlıklarını Fiyatlama Modeli (SVFM) kullanılmıştır. Sonuç olarak sermaye artırımı yoluyla satışa hazır bekletilen payların satışının pay getirilerini olumlu yönde etkilediği fakat bu uygulamayı takip ederek yatırımcıların büyük miktarlarda ve uzun süreli pozitif getiriler elde edemeyeceği, ancak klsa dönemli pozitif anormal getiri elde edebilmenin mümkün olduğu tespit edilmiştir. Ayrica test edilen dönem ve şirketler açısından BIST pay piyasasının yarı güçlü formda etkin bir piyasa olmadı̆̆ını yönünde bulgulara ulaşılmıştır.
\end{abstract} Istanbul

Anahtar Kelimeler: İlk Halka Arz, Satışa Hazır Bekletilen Paylar, Olay Çalışması, Borsa

JEL Sinıflandirması: G12, G14, O16

\section{The Impacts of Sales of Shares Kept Ready for Sales Through Capital Increase in Going Public on Equity Returns}

\begin{abstract}
The purpose of this study was to investigate the impacts of sales of shares kept ready for sale through capital increase after the initial public offering on equity returns. The scope of the study consists of BIST companies that selling shares kept ready for sale between 2013 and 2020. In the study, in which the event study method was used, the sales date of the shares kept ready for sale was determined as the event day. As the event window, 5 days before and after the event day (-1+5) were examined. The Capital Asset Pricing Model (CAPM) was used to calculate the expected returns of the equities. As a result, it was determined that the sale of shares kept ready for sale through capital increase positively affected the equity returns, but following this application, it would not be possible for investors to o obtain short term positive abnormal returns. In addition, it was found that BIST equity market is not efficient in the semi-strong form in terms of the period and companies tested.btain large amounts of long term positive returns, but it would be possible to obtain short term positive abnormal returns. In addition, it was found that BIST equity market is not efficient in the semi-strong form in terms of the period and companies tested.
\end{abstract} Istanbul

Key Words: Initial Public Offering, Shares Kept Ready for Sales, Event Study, Borsa

JEL Classification: M31 G12, G14, O16

\footnotetext{
*Arş. Gör. Balıkesir Üniversitesi İktisadi ve İdari Bilimler Fakültesi, İşletme Bölümü, arif.sezgin@balikesir.edu.tr, ORCID Bilgisi: 00000-0002-3381-6458

*** Doç. Dr. Balıkesir Üniversitesi İktisadi ve İdari Bilimler Fakültesi, İşletme Bölümü, saytekin@ balikesir.edu.tr, ORCID Bilgisi: 0000-0003-1502-2643
} 


\section{GİRIŞ}

Küreselleşme süreci birey ve toplumları olduğu gibi şirketleri de derinden etkilemiştir. İş planı, ticaretin yapılma şekli, yönetim tarzı vb. pek çok kavramın yeniden şekillendirilmesini gerekli kılmıştır. Ticarette sınırların kaldırılması ve genişleyen potansiyel pazarlarla birlikte sürece uyum sağlayan şirketler, ortaya çıkan firsatları yakalama şansına erişmiştir. Bununla birlikte söz konusu firsatlardan yararlanılması şirketlerin sermaye miktarına da doğrudan bağlıdır. $\mathrm{Ne}$ var ki, şirketler faaliyetlerinde kullanabilecekleri sınırlı bir sermaye gücüne sahiptir.

Yatırım yapılabilmesi, çalışma sermayesi ihtiyacının karşılanması, araştırma ve geliştirme vb. faaliyetler işletmeler açısından sermaye gereksinimine neden olabilmektedir. Finansman ihtiyacının karşılanmasında ise borç ile finansman ve özkaynak ile finansman olmak üzere iki temel kaynak bulunmaktadır (Gündoğdu, 2017: 426). Borç ile finansman firmalar için sık kullanılan bir kaynak olmakla birlikte, şirketin riskini artması ve belirli bir kaldıraç oranından sonra ilave kaynak bulmanın maliyetindeki yükselişler (Yiğit, 2016: 16-17; Omağ, 2015: 208) nedeniyle sürekli başvurulabilecek bir yöntem değildir. Özkaynak ile finansman ise şirketler açısından bir diğer finansman kaynağını oluşturmaktadır.

Özkaynak yoluyla finansman tercihinde şirketler ya kendi bünyesinde oluşan kaynaklar (dağıtılmamış karlar, içsel kaynakların sermayeye eklenmesi) ya da hisse ihracı ile kaynak temini gibi dışarıdan kaynak sağlama yolunu tercih edebilmektedir (Yaşar, 2006: 3). Özkaynak ile finansman tercihlerine şirkete sağlanan nakit yönüyle bakıldığında; içsel kaynakların sermayeye eklenmesiyle gerçekleştirilen bedelsiz sermaye artırımında şirkete yeni bir nakit akımı sağlamamakta, buna karşın bedelli sermaye artırımında ihraç edilen paylar üzerinden ilave nakit akışı sağlanmaktadır. Ayrıca halka kapalı şirketlerin, mevcut payların satışı ve sermaye artırımı yoluyla çıkaracağ 1 hisse senetlerini halka arz etmek suretiyle halka açılması özkaynak ile finansmanda önemli bir alternatif olarak öne çıkmaktadır.

Halka açık olmayan şirketlerin paylarını halka arz ederek halka açılmasında kullanılabilecek çeşitli halka arz yöntemleri bulunmaktadır. Bunlar; mevcut payların satışı, sermaye artırımı yoluyla halka arz ve her iki yöntemin bir arada kullanılması olarak sıralanabilir. Yapılan halka arzlar incelendiğinde genel olarak her iki yönteminde birlikte kullanıldığ 1 görülmektedir. Bu durumda, hem mevcut şirket ortakları payların satışı ile gelir elde etmekte hem de sermaye artırımı yoluyla yeni yatırımcılara satılan paylar üzerinden şirket finansman kaynağına erişim sağlamaktadır (Borsa İstanbul [BİST], 2020).

Paylar ile pay benzeri menkul kıymetlerin 6362 sayılı Sermaye Piyasası Kanunu (SPK) çerçevesinde ihracına ilişkin usul ve esaslar Pay Tebliği (VII128.1) ile belirlenmiştir. Pay Tebliği (Madde 9)'ne göre, payları ilk defa halka arz edilecek ortaklıkların ek satıs haricindeki halka arz edilecek paylarının halka arz fiyatı baz alınarak hesaplanan piyasa fiyatının 40 milyon TL'nin altında olması durumunda, halka arza ilişkin izahnamenin onaylanmasından önce halka arz 
edilecek payların nominal değerine göre \%25'ini oluşturan paylar mevcut ortakların yeni pay alma haklarına kısıtlama getirilerek satışa hazır bir şekilde bekletilmektedir. Tebliğ kapsamındaki satışa hazır bekletilen payların satışının aracı kurum tarafindan yerine getirileceği 10. maddenin 1. fikrasında belirtilmiştir. Ayrıca, satışa hazır bekletilen payların satış işleminin, izahnamenin Kamuyu Aydınlatma Platformu (KAP)'nda yayınlandığı tarihten itibaren (yayınlanma tarihi baz alınarak) bir yıllık süre içerisinde bir veya birden çok seferde gerçekleştirilebileceği açıklanmıştır (SPK, 2013).

Tebliğe göre satışa hazır bekletilen payların satışına başlanabilmesi için payların borsa fiyatının halka arz fiyatının $\% 25$ fazlasından daha yukarıda olması koşulu yer almakla birlikte, satışa hazır bekletilen payların satışı konusunda herhangi bir zorunluluk öngörülmemiştir (SPK, 2013). Dolayısıyla, şirketler satışa hazır bekletilen payların satılıp satılmaması konusunda bir serbestliğe sahiptir. Ayrıca, satışa hazır bekletilen payların satışına başlanılması ve satış sonuçları kapsamındaki bilgilendirmeler aracı kurum tarafından Özel Durum Açıklaması (ÖDA) ile KAP'ta kamuya duyurulması gerekmektedir (SPK, 2013).

Buradan hareketle çalışmada, bedelli/bedelsiz sermaye artırımından ve ikincil halka arzdan farklı bir uygulama olmakla beraber şirketin sermayesini artırmasını sağlayan satışa hazır bekletilen pay satışlarının hisse senedi getirileri üzerindeki etkileri araştırılmıştır. Literatürde bedelli/bedelsiz sermaye artırımları, ilk halka arzlar ve ikincil halka arzları konu edinen pek çok çalışma yer almaktadır. Bu çalışmalarda sermaye artırımları genellikle hisse senedi getirileri üzerine etkileri veya fiyat anomalileri yönüyle incelenmiştir. Bununla birlikte, ulusal literatürde sermaye artırımı yoluyla satışa hazır bekletilen payların incelendiği bir çalışmaya rastlanılmamıştır. Bu durumun ise yapılan çalışmanın özgün yönünü oluşturduğu ve bu yönüyle literatüre katk1 sunacağ 1 düşünülmektedir. Ayrıca bu çalışmada Borsa İstanbul pay piyasasının incelenen şirketler açısından yarı güçlü formda etkin olup olmadığı da test edilmiştir.

\section{LITERATÜR TARAMASI}

Finans literatüründe şirketlerin bedelli ve bedelsiz sermaye artırımlarına ilişkin çokça çalışma mevcuttur. Bu çalışmalarda genellikle sermaye artırımının şirketlerin hisse senedi getirileri üzerindeki etkileri çeşitli yöntemler kullanılarak ölçülmeye çalışılmıştır. Çalışmamızda, şirketlerin halka arz izahnamelerinde belirtmekle birlikte halkta arzdan sonra belirli koşulların oluşması durumunda kullanabilecekleri bir hak olan satışa hazır bekletilen payların satılması durumu incelenmiştir. Yapı itibariyle ikincil halka arz ve bedelli sermaye artırımına benziyor olsa da mevzuat ve uygulanma şekli olarak bunlardan farklıdır. Literatürde satışa hazır bekletilen paylarla ilgili çalışmaya rastlanılamadığı için bu kısımda bedelli sermaye artırımlarını olay etüdü ile inceleyen ulusal ve uluslararası alanda yapılmış benzer çalışmalarla konu ilişkilendirilmeye çalışılmıştır.

Özer ve Yücel (2001) çalışmalarında, 1990-1996 tarihleri arasında İMKB (BİST)'de işlem görmüş olan şirketlerin ihraç tarihleri civarındaki fiyat hareketlerini incelemişlerdir. Olay çalışması yöntemi kullanılarak yapılan 
analizler sonucunda olay tarihi etrafındaki günlerde istatiksel olarak anlamlı getiriler elde edilmekle birlikte bu getirilerin yönünün olay tarihi öncesinde pozitif olduğu, olay tarihinden 2 gün sonrasında negatife döndüğü ortaya çıkmıştır. Ayrıca, yatırımcıların bedelli veya bedelsiz şeklindeki sermaye artırımına gösterdikleri fiyat tepkilerinin farklılaşmadığ 1 sonucuna varılmıştır.

Adaoğlu (2006) çalışmasında BİST'e kote firmalar özelinde bedelli sermaye artırımı ve bedelsiz sermaye artırımı duyurularına piyasa tepkisini araştırmıştır. 1994-1999 yıllarını kapsayan çalışmada toplam 294 sermaye artırım duyurusu incelenmiştir. Bedelli sermaye artırım duyurusu ilan gününde istatiksel olarak anlamlı ve negatif getiriler gözlemlenmiş, bedelli sermaye artırımına bedelsiz sermaye artırımının eşlik etmesi durumunda ise pozitif ve istatiksel olarak anlamlı getirilerin elde edildiği bulgusuna ulaşılmıştır.

Küçüksille ve Mizrahi (2015) çalışmalarında bedelli sermaye artırımının payları BİST'de işlem gören şirketlerin hisse senedi performansına etkisini araştırmışlardır. 2010-2014 dönemini kapsayan çalışmada olay etüdü yönteminden yararlanılmıştır. 10 günlük olay penceresi kullanılarak, olay tarihinde ve takip eden günde istatistiksel olarak anlamlı negatif getiriler tespit edilmiştir. Sonuç olarak, BİST hisse senedi piyasasının yarı güçlü formda etkin bir piyasa olmadığı ve hisse senedi fiyatlarının bedelli sermaye artırım duyurularından etkilendiği tespit edilmiştir.

Kendirli ve Elmalı (2016), payları BİST'e kote olan mevduat bankalarının yaptığ üzerindeki etkisini araştırmışlardır. Bu kapsamda 2009-2014 yılları arasındaki dönemde mevduat bankalarınca yapılan 5 bedelli sermaye artırım duyurusunu olay çalışması yöntemiyle incelemişlerdir. Olay penceresi olarak $-20 /+20$ gün kullanılan çalışmada olay günü için bedelli sermaye artırımının hisse senedi üzerinde istatiksel olarak anlamlı bir etkisinin olmadığ 1 tespit edilmiştir. Ayrıca, duyuru sonrası 10 günlük bir dönem için kümülatif ortalama anormal getirilerin istatiksel olarak anlamlı ve negatif olduğu ortaya konulmuştur.

Kederli ve Başkaya (2017) çalışmalarında, 2015-2016 döneminde BİST Yıldız Pazar'da işlem gören 27 şirketin yapmış olduğu 37 adet bedelli/bedelsiz sermaye artırımı duyurusunu incelemiş ve şirketlerin hisse senedi fiyatları üzerindeki etkisini araştırmışlardır. Olay çalışması yönteminin kullanıldığı çalışmada, olay penceresi olarak olay tarihinden 10 gün öncesi ve sonrası $(-/+10)$ ile 5 gün öncesi ve sonrası $(-/+5)$ incelenmiştir. Elde edilen bulgular, bedelli sermaye artırımını takip eden günlerde bedelsiz sermaye artırımı yapan şirketlere göre kümülatif anormal getirilerde sert bir düşüşün yaşandığını göstermiştir. Sonuç olarak sermaye artırımı duyuruları ile kısa dönemli anormal getiri elde etmenin mümkün olduğunu ve bu doğrultuda piyasanın yarı güçlü formda bile etkin olmadığını ortaya koymuşlardır.

Tsnagarakis (1994) çalışmasında bedelli sermaye artırımı duyurularının hisse senedi getirileri üzerindeki etkisini Atina Borsası özelinde incelemiştir. 1981-1990 dönemini kapsayan çalışmada olay çalışması yöntemi kullanılarak 34 firmanın bedelli sermaye artırım duyurusu ele alınmıştır. Çalışmada, bedelli 
sermaye artırımının yapıldığı günde ve takip eden günlerde istatistiksel olarak anlamlı anormal bir getirinin mevcut olmadığı sonucuna ulaşmıştır. Çalışma bulgularından hareketle Atina borsasının yarı güçlü formda etkin bir piyasa olduğu ve bedelli sermaye artırımı duyurularının hisse senedi getirileri üzerinde anlamlı bir etkiye sahip olmadığı ortaya konulmuştur.

Chen ve Chen (2007) Çin hisse senedi piyasasına kote firmaların yaptıkları bedelli sermaye artırımı duyularına hisse senedi piyasasının tepkisini incelemişlerdir. 1999-2001 döneminde gerçekleșen 205 bedelli sermaye artırım duyurusunun etkisini olay çalışması yöntemi ile analiz etmişlerdir. Çalışma sonucunda, yapılan duyuru etrafindaki günlerde piyasa tepkisi negatif olarak tespit edilmiştir.

Owen ve Suchard (2008) çalışmalarında, Avusturalya hisse senedi piyasasına kote firmaların yaptıkları bedelli sermaye artırımı duyurularının hisse senedi getirisi üzerindeki etkisini ve rüçhan hakkının fiyatlandırılmasını incelemişlerdir. 1993-2001 dönemini kapsayan çalışmada 107 firma tarafindan gerçekleştirilen 207 adet bedelli sermaye artırım duyurusu incelenmiştir. Olay etüdü yönteminin kullanıldığı çalışmada, olay penceresi olarak olay tarihinin 5 gün öncesi ve sonrası $(-/+5)$ seçilmiştir. Çalışmanın bedelli sermaye artırım etkisine yönelik bulguları; duyuru gününde istatiksel olarak anlamlı ve negatif getiri elde edilmekte iken, duyuru sonrası günlerde istatiksel olarak anlamsız olmakla birlikte negatif getiriye işaret etmekte olduğu şeklindedir.

Bashir (2013) çalışmasında Pakistan Karachi Borsasına kote şirketlerin 2008-2011 tarih aralığında yaptıkları 31 bedelli sermaye artırımı duyurusuna piyasa tepkisini araştırmıştır. Olay etüdü yöntemi kullanılarak yapılan çalışmada, olay penceresi olarak olay duyuru tarihinden 10 gün öncesi ve sonrasi $(-/+10)$ incelenmiştir. Duyuru tarihinde \%0.42 gibi göz ardı edilebilecek anlamsız bir pozitif getiri elde edilmiş, duyuru tarihinden önceki iki günde istatiksel olarak anlamlı ve negatif getirilerin oluştuğu ortaya konulmuştur. Ayrıca yatırımcıların duyuru günlerini takip ederek kazançlarını önemli miktarda artıramayacakları sonucuna ulaşılmıştır.

Ramesh ve Rajumesh (2014) Sri Lanka hisse senedi piyasasına kote firmaların yaptıkları bedelli sermaye artırım duyurusuna piyasa tepkisini araştırmışlardır. 2008-2012 dönemini kapsayan çalışmada 61 firma tarafından gerçekleştirilen 78 adet bedelli sermaye artırım duyurusu incelenmiştir. Olay çalışması yöntemi kullanılarak yapılan çalışmada, olay penceresi olarak duyuru tarihinden 10 gün öncesi ve sonrası $(-/+10)$ seçilmiştir. Çalışma sonucunda olay gününde pozitif ve istatiksel olarak anlaml getiri elde edildiği ve pozitif getirilerin olay günü sonrasında da devam ettiği tespit edilmiştir.

Mahmood vd. (2014) çalışmalarında, Pakistan Karachi Borsasına kote firmaların 2005-2012 yılları arasında yaptıkları bedelli sermaye artırım duyurularına piyasa tepkisini araştırmışlardır. Çalışmada yöntem olarak olay çalışması yöntemi kullanılmış, olay tarihinden olay penceresi olarak 30 gün öncesi 20 gün sonrası, 20, 10 ve 5 gün öncesi ve sonrası olarak farklı tarih 
aralıkları seçilmiştir. Çalışma sonucunda bedelli sermaye artırımı duyurularına piyasa tepkisinin negatif olduğu tespit edilmiştir.

Otieno ve Ochieng (2015) Kenya Nairobi Menkul Kiymetler Borsasına kote 12 şirketin bedelli sermaye artırımı duyurularının hisse senedi getirisi üzerindeki etkisini olay çalışması yöntemi ile araştırmışlardır. 2007-2014 dönemini kapsayan çalışmada olay penceresi olarak duyuru tarihinden 30 gün öncesi ve sonrası seçilmiştir. Çalışma sonucunda bedelli sermaye artırım duyurularının hisse senedi üzerinde istatiksel olarak anlamlı negatif getirilere yol açtığ tespit edilmiştir.

Alhashel (2016) çalışmasında Kuveyt Borsasına kote şirketlerin yaptıkları bedelli sermaye artırımı duyurularına hisse senedi piyasasının tepkisini ve bu doğrultuda piyasanın etkinliği araştırmıştır. 2004-2013 dönemini kapsayan çalışmada olay çalışması yöntemi kullanılmıştır. Çalışma sonucunda Kuveyt hisse senedi piyasasının yarı güçlü formda etkin olduğu sonucuna ulaşılmıştır.

Rohit vd. (2016) Hindistan Bombay Borsasına kote şirketlerin 2011-2014 yılları arasında yapmış oldukları hisse senedi bölünme ve bedelli sermaye artırım duyurularının hisse senedi getirileri üzerindeki etkisini araştırmışlardır. 90 hisse senedi bölünmesi ve 29 bedelli sermaye artırımı duyurusunun kullanıldığ çalışmada olay çalışması yöntemi benimsenmiş̧ir. Olay penceresi olarak duyuru öncesi ve sonrasındaki 30 gün $(-/+30)$ aralığ kullanılmıştır. Çalışma sonucunda her iki duyuru gününde pozitif getirilerin oluştuğu ancak istatiksel olarak anlamsız olduğu tespit edilmiştir. Ayrıca çalışma bulgularından hareketle Hindistan hisse senedi piyasasının yarı güçlü forma etkin olduğu sonucuna varılmıştır.

Suresha ve Chandrashekara (2016) Hindistan hisse senedi piyasasında (Nifty endeksine kote) yaptıkları çalışmada bedelli sermaye artırımı, bedelsiz sermaye artırımı ve hisse senedi bölünmelerinin anormal getirilere yol açıp açmadığını araştırmışlardır. 1996-2015 tarih aralığını kapsayan çalışmada 56 bedelsiz sermaye artırımı, 33 hisse bölünmesi ve 13 bedelli sermaye artırımı duyurusu olay çalışması yöntemi ile incelenmiştir. Olay penceresi olarak olay tarihinden 20 gün öncesi ve sonrası $(-/+20)$ seçilmiştir. Sonuç olarak, bedelsiz sermaye artırım duyurusu gününde istatiksel olarak anlamlı pozitif getiriler elde edilmekte iken hisse senedi bölünmesi ve bedelli sermaye artırım duyurusu gününde istatiksel olarak anlamlı negatif getiriler tespit edilmiştir.

Ogada ve Kalunda (2017), 2005-2012 tarihleri arasında Kenya Nairobi Menkul Kiymetler Borsasına kote 18 şirketin bedelli sermaye artırımı duyurularının hisse senedi getirileri üzerindeki etkisini araştırmışlardır. Olay çalışması yöntemi kullanılarak yapılan çalışmada olay penceresi olarak duyuru öncesi ve sonrasındaki 30 gün $(-/+30)$ aralığ kullanılmıştır. Elde edilen bulgular duyuru öncesi ve sonrası dönemde pozitif getirilerin oluştuğunu ancak istatiksel olarak anlamsız çıktığını ve bu doğrultuda piyasanın yarı güçlü formda etkin olduğunu göstermektedir.

Bedelli sermaye artırımının hisse senedi getirileri üzerindeki etkisini olay çalışması yöntemiyle inceleyen ulusal ve uluslararası sermaye piyasalarında 
yapılan çalışmalarda, ele alınan dönem ve piyasaya göre birbiri ile çelişen bulgulara ulaşılmıştır. Bu bağlamda, bütünsel olarak piyasaların etkinlik düzeyleri açısından henüz bir fikir birliğine varılamadığı söylenebilir.

\section{YÖNTEM}

Bu çalışmanın amacı, BIST Pay Piyasası şirketlerinin sermaye artırımı yoluyla satışa hazır bekletilen pay satışlarının hisse senedi getirileri üzerindeki etkilerini araştırmaktır. $\mathrm{Bu}$ doğrultuda 2013-2020 döneminde satışa hazır bekletilen paylarını ihraç eden şirketler analize dahil edilmiştir. Söz konusu dönemde, pay tebliğinde belirtilen tutarların dışında bir halka arz büyüklüğü olması, satışa hazır bekletilen payların süresi içerisinde satılmaması gibi gerekçelerden dolayı paylarını halka arz eden 51 şirketin 38'inde satışa hazır bekletilen payların satışı gerçekleşmemiştir.

Kalan 13 şirket ise çalışmaya dahil edilmekle birlikte olay penceresi olarak kullanılan 5 gün öncesi ve 5 gün sonrasına $(-/+5)$ göre uyumlu verisi olmayan 4 şirket analiz kapsamından çıkartılmıştır. Bu doğrultuda verisine ulaşılabilen ve yöntem ile uyumlu veri sağlanabilen toplam 9 şirket ile analize devam edilmiştir.

Tablo 1. 2013-2020 Yılları Arasında Satışa Hazır Bekletilen Payların Satışını Yapan Şirketler

\begin{tabular}{|c|c|c|c|c|}
\hline Kod & Şirket Adı & Halka Arz Tarihi & $\begin{array}{c}\text { BÍST'te İşlem } \\
\text { Görmeye Başlama } \\
\text { Tarihi }\end{array}$ & $\begin{array}{c}\text { Satışa Hazır } \\
\text { Bekletilen Payların } \\
\text { İlk Satış Tarihi }\end{array}$ \\
\hline ARDYZ & ARD Bilişim Teknolojileri & 29.01 .2020 & 06.02 .2020 & 10.02 .2020 \\
\hline PAPIL & Papilon Savunma & 28.11 .2019 & 06.12 .2019 & 09.12 .2019 \\
\hline DERAS & Derlüks Deri & 27.06 .2019 & 04.07 .2019 & 03.12 .2019 \\
\hline CEOEM & Ceo Event Medya & 23.05 .2019 & 31.05 .2019 & 05.05 .2020 \\
\hline SMART & Smartiks Yazılım & 09.05 .2019 & 16.05 .2019 & 17.05 .2019 \\
\hline KFEIN & Kafein Yazılım & 10.05 .2018 & 16.05 .2018 & 05.06 .2018 \\
\hline SAFKR & Safkar Ege Soğutmacılık & 10.01 .2018 & 16.01 .2018 & 18.01 .2018 \\
\hline IZFAS & İzmir Fırça & 02.07 .2014 & 07.07 .2014 & 27.08 .2014 \\
\hline YAYLA & Yayla En. Ür. Tur. Ve İnş & 14.11 .2013 & 22.11 .2013 & 07.11 .2014 \\
\hline IZTAR & İz Hayvancılık Tarım & 06.11 .2013 & 12.01 .2013 & 21.03 .2014 \\
\hline SAYAS & Say Reklamcılık & 24.06 .2013 & 28.06 .2013 & 27.01 .2014 \\
\hline TACTR & Taç Tarım Ürünleri & 20.05 .2013 & 27.05 .2013 & 24.12 .2013 \\
\hline RODRG & Rodrigo Tekstil & 30.07 .2013 & 13.08 .2013 & 30.10 .2013 \\
\hline Kaynak: Kamuyu Aydınlatma Plater & & & \\
\hline
\end{tabular}

Kaynak: Kamuyu Aydınlatma Platformu (KAP)

Tablo 1'de satışa hazır bekletilen payların satışını yapan BIST şirketlerine ilişkin bilgiler yer almaktadır. Bu şirketlerden ARDYZ, PAPIL, SMART ve SAFKR, halka arz tarihinden 1-3 sonrasında satışa hazır bekletilen pay satışını gerçekleştirmişlerdir. Bu satışlar, çalışmanın olay penceresi içerisinde kaldığından ilgili şirketler kapsam dışı bırakılmıştır.

Çalışma kapsamında kullanılan verilerden; hisse senetlerinin günlük kapanış fiyatları ile BİST 100 fiyat endeksinin günlük kapanış değerlerine FINNET veri tabanından, risksiz faiz oran 1 verilerine TCMB internet sitesinde yer 
alan ihale yöntemi ile satılan hazine bonosu ve devlet tahvillerinin yıllık faiz oranlarından ulaşılmıştır. Risksiz faiz oranı vadesi 1 yıldan kısa olan devlet iç borçlanma senetlerinin ilgili tarih aralığı için yıllık faiz oranları kullanılarak hesaplanmıştır.

Pay piyasası şirketlerinin satışa hazır bekletilen pay satışlarının hisse senedi getirisi üzerindeki etkilerini incelemek üzere olay çalışması (etüdü) (event study) yöntemi benimsenmiştir. Bir olayın, üzerinde etkisi olduğu düşünülen finansal enstrümanın getirini ne yönde etkilediğini ölçebilmek için bir takım kavramların net olarak belirlenmesi gerekmektedir. Bunlar, etkisi olduğu düşünülen olayın tarihi, olaydan önceki ve sonraki bir dönemi ifade edebilen olay penceresi ve bazı parametrelerin hesaplanabilmesi için ihtiyaç duyulan tahmin penceresidir (Mishra, 2005: 10; Erol ve Aytekin, 2018: 902). Olay çalışması yönteminde incelenen konuya bağlı olarak olay tarihinden 1 gün, 5 gün, 20 gün veya 30 gün öncesi veya sonras1 olay penceresi olarak belirlenebilmektedir (Küçüksille ve Mizrahi, 2015: 65). Bu çalışmada olay penceresi olarak olay tarihinden 5 gün öncesi/sonrası (-/+5 gün) belirlenmiştir. Olay penceresinin daha geniş bir aralık olarak alınmamasının temel nedeni, incelenmek istenilen olay haricindeki etkilerin sınırlandırılmak istenmesidir. Çalışmada beklenen getiri hesaplama modeli olarak Sermaye Varlıklarını Fiyatlama Modeli (SVFM) kullanılmıştır. Satışa hazır bekletilen pay satışlarının hisse senedi getirileri üzerindeki etkisinin belirlenmesinde AR ve CAR değerlerinin istatiksel olarak anlamlılığı $\mathrm{t}$ testi ile analiz edilmiştir.

Olay çalışması yönteminde yapılan hesaplamalar aşă̆ıda sırasıyla açıklanmıştır.

1. aşamada ilgili şirketin hisse senetlerinin veya BIST 100 endeksinin günlük kapanış değerlerinden hareketle $\mathrm{t}$ zamanındaki logaritmik getirileri aşağıdaki formül yardımıyla hesaplanmıştır (Köseoğlu, 2010: 125):

$\mathrm{R}_{\mathrm{it}}=\ln \left(\mathrm{P}_{\mathrm{it}} / \mathrm{P}_{\mathrm{i}, \mathrm{t}-1}\right)$

$\mathrm{R}_{\mathrm{it}}=\mathrm{i}$. hisse senedinin veya endeksin t. zamandaki logaritmik getirisini

$\mathrm{P}_{\mathrm{i}, \mathrm{t}}=\mathrm{i}$. hisse senedinin veya endeksin t. zamandaki kapanış fiyatını

$\mathrm{P}_{\mathrm{i}, \mathrm{t}-1}=\mathrm{i}$. hisse senedinin veya endeksin $\mathrm{t}-1$ zamanındaki kapanış fiyatını göstermektedir.

2. aşamada anormal getirisi bulunacak şirketin beta katsayısı, aynı sektörde faaliyet gösteren benzer şirketlerin beta katsayıları üzerinden kaldıraçlı beta hesaplaması yoluyla elde edilmiştir. Bu durumun nedeni incelenen şirketlerin BIST'te işlem görmeye başladığı tarih ile satışa hazır bekletilen paylarının satışı arasında kısa zaman aralıklarının bulunmasıdır.

Kaldıraçlı beta hesaplamasında izlenmesi gereken adımlar aşağıdaki gibidir (Ercan vd., 2007: 302; Çırak, 2018: 116-118):

1- Değerlemesi yapılacak olan şirket ile aynı sektörde faaliyet gösteren ve halka açık olan şirketlerin belirlenmesi.

2- Belirlenen halka açık şirketlerin beta katsayılarının regresyon modeli ile hesaplanması ve beta üzerindeki kaldıraç etkisinin finansal borç/özkaynak 
oranı kullanılarak giderilmesi. Bu aşamada kullanılan kaldıraçsız beta formülü aşağıdaki gibidir:

$$
\beta_{\mathrm{U}}=\beta_{\mathrm{L}} /(1+(1-\mathrm{t}) *(\text { Finansal Borçlar/Özkaynaklar }))
$$

$\beta_{\mathrm{U}}=$ Kaldıraçsız Beta

$\beta_{\mathrm{L}}=$ Şirket(ler) veya Sektör Ortalama Betas1

$\mathrm{t}=$ Şirket(ler) veya Sektör Efektif Vergi Oranı

3- Karşılaştırmada kullanılan şirketlerin hesaplanan kaldıraçsız beta katsayılarının ortalama değerleri üzerinden ilgili şirketin finansal borç/özsermaye değerini hesaba katan kaldıraçlı beta değerinin hesaplanması. Bu aşamada kullanılan formül aşağıdaki gibidir:

Hesaplanan Beta $\left(\beta_{\mathrm{L}}\right)=\beta_{\mathrm{U}^{*}}(1+(1-\mathrm{t}) \mathrm{x}($ Finansal Borçlar/Özkaynaklar $))(3)$

$\beta_{\mathrm{L}}=$ Hesaplanan şirketin kaldıraçlı betası

$\beta_{U}=$ Sektörün kaldıraçsız beta ortalaması

$\mathrm{t}=$ Şirketin Efektif Vergi Oranı

3. aşamada hisse senedinin beklenen getiri oranı hesaplanmıştır. Beklenen getiri hesaplamasinda literatürde siklikla kullanılan Sermaye Varlıklarını Fiyatlama Modeli (SVFM) kullanılmıştır. SVFM modelinde kullanılan denklem aşağıdaki gibidir (Karan, 2013: 210):

$$
\begin{aligned}
& E\left(R_{i t}\right)=r_{f}+\beta_{i}\left(E\left(R_{m}\right)-r_{f}\right) \\
& E\left(R_{i t}\right)=\text { beklenen getiriyi } \\
& r_{f}=\text { risksiz faiz oranın1 } \\
& E\left(R_{m}\right)=\text { piyasa getirisini göstermektedir. }
\end{aligned}
$$

4. aşamada olay penceresi içerisinde hisse senedinin getirisi ile beklenen getirisi arasındaki farkı ifade eden anormal getiriler hesaplanmıştır. Hesaplamada kullanılan formül aşağıdaki gibidir (Başdaş ve Oran, 2014: 170):

$$
\mathrm{AR}_{\mathrm{it}}=\mathrm{R}_{\mathrm{it}}-\mathrm{E}\left(\mathrm{R}_{\mathrm{it}}\right)
$$

$\mathrm{AR}_{\mathrm{it}}=\mathrm{i}$. hisse senedinin t. zamandaki anormal getirisini

$\mathrm{R}_{\mathrm{it}}=\mathrm{i}$. hisse senedinin $\mathrm{t}$. zamandaki gerçekleşmiş getirisini etmektedir.

$E\left(R_{i t}\right)=i$. hisse senedinin t. zamanındaki beklenen getirisini ifade

5. aşamada hesaplanan anormal getirilerin ortalaması alınmıştır. Bunun için kullanılan denklem aşağıdaki gibidir (Bashir, 2013: 9):

$$
\mathrm{AAR}_{\mathrm{t}}=1 / \mathrm{N} \sum_{i=1}^{N} A R_{i t}
$$

$\mathrm{AR}_{\mathrm{it}}=\mathrm{i}$. hisse senedinin t. zamandaki anormal getirisini

$\mathrm{N}=\mathrm{t}$ gününde getirisi hesaplanan şirket sayısı

$\mathrm{AAR}_{\mathrm{t}}=$ Ortalama anormal getiri

6. aşamada kümülatif anormal getiri hesaplanmıştır. Hesaplamada kullanılan formül aşağıdaki gibidir (Ma vd., 2009: 243):

$\mathrm{CAR}_{\mathrm{i}(\mathrm{t} 1-\mathrm{t} 2)}=\sum_{t=t 1}^{t_{2}} A R_{i t}$

$\mathrm{CAR}_{\mathrm{i}(\mathrm{t} 1-\mathrm{t} 2)}=$ Kümülatif anormal getiri

$A R_{i t}=\mathrm{i}$. hisse senedinin t. zamandaki anormal getirisini göstermektedir.

7. aşamada her bir hisse senedinin olay penceresi içerisinde gerçekleşen ortalama anormal getirilerinin toplamı alınmıştır. Kullanılan formül aşağıdaki gibidir (Bashir, 2013: 9): 
$\mathrm{CAAR}_{(\mathrm{t} 1, \mathrm{t} 2)}=\sum_{t=t 1}^{t_{2}} A A R_{t}$

$\mathrm{CAAR}=$ Kümülatif ortalama anormal getiri

AAR $=$ Ortalama anormal getiri

$\mathrm{t} 1, \mathrm{t} 2=$ Olay penceresindeki günleri ifade etmektedir.

Yukarıda açıklanan aşamalardan hareketle AR ve CAR değerleri hesaplanmıştır. Kümülatif anormal getirilerin sıfirdan farklılaşması, gerçekleşen olayın hisse senedi üzerinde etkiye sahip olduğunun bir göstergesidir. Ayrıca, satışa hazır bekletilen pay satışı üzerinden anormal getirinin elde edilebilmesi, ilgili piyasanın yarı güçlü formda etkin olmadığına da işaret etmektedir (Kaderli, 2007: 148). AR ve CAR değerlerinin hesaplanmasının ardından satışa hazır bekletilen pay satışlarının hisse senedi getirileri üzerindeki etkilerinin ortaya konulması ve elde edilen sonuçların istatiksel olarak anlamlı olup olmadığının belirlenmesi gerekmektedir.

Buradan hareketle çalışmanın hipotezleri şu şekilde belirlenmiştir.

$\mathbf{H}_{\mathbf{0}}=$ Satışa hazır bekletilen payların satışının şirketlerin hisse senedi getirileri üzerinde etkisi yoktur. $\left(\mathrm{CAR}_{\mathrm{t}}=0, \mathrm{AR}_{\mathrm{t}}=0\right)$

$\mathbf{H}_{1}=$ Satışa hazır bekletilen payların satışının şirketlerin hisse senedi getirileri üzerinde etkisi vardır. $\left(\mathrm{CAR}_{\mathrm{t}} \neq 0, \mathrm{AR}_{\mathrm{t}} \neq 0\right)$

\section{BULGULAR}

Çalışmanın bu bölümünde, yöntem kısmında aşamalar halinde yer alan hesaplamalardan hareketle elde edilen bulgular bulunmaktadır.

Tablo 2. Olay Penceresinde Şirketlerin Kümülatif Anormal Getirileri $\left(\mathrm{CAR}_{\mathrm{t}}\right)$

\begin{tabular}{|c|c|c|c|c|c|c|c|c|c|}
\hline $\begin{array}{c}\text { Olay } \\
\text { Penceresi }\end{array}$ & DERAS & CEOEM & KFEIN & IZFAS & YAYLA & IZTAR & SAYAS & TACTR & RODRG \\
\hline-5 & 0,1394 & $-0,0073$ & 0,0161 & 0,0442 & $-0,0028$ & 0,0006 & 0,0045 & 0,0012 & $-0,0278$ \\
\hline-4 & 0,1741 & $-0,0030$ & 0,0214 & 0,0631 & 0,0138 & $-0,0114$ & $-0,0162$ & $-0,0204$ & $-0,0051$ \\
\hline-3 & 0,1512 & 0,0364 & 0,0162 & 0,1128 & 0,0107 & $-0,0197$ & $-0,0287$ & $-0,0102$ & $-0,0488$ \\
\hline-2 & 0,1045 & 0,0126 & 0,0455 & 0,1135 & 0,0278 & 0,0023 & $-0,0027$ & $-0,0213$ & $-0,0086$ \\
\hline-1 & 0,1277 & 0,0338 & 0,0891 & 0,0815 & 0,0954 & 0,0043 & 0,0095 & $-0,0183$ & $-0,0212$ \\
\hline 0 & 0,2649 & 0,1290 & 0,1011 & 0,1776 & 0,1138 & 0,0109 & $-0,0001$ & $-0,0293$ & $-0,0166$ \\
\hline 1 & 0,4395 & 0,1851 & 0,0785 & 0,2878 & 0,1200 & 0,0089 & 0,0198 & $-0,0294$ & $-0,0099$ \\
\hline 2 & 0,6136 & 0,2384 & 0,0601 & 0,2452 & 0,0947 & 0,0017 & 0,0487 & $-0,0278$ & 0,0405 \\
\hline 3 & 0,3899 & 0,1748 & 0,1053 & 0,2342 & 0,0686 & $-0,0198$ & 0,0365 & $-0,0232$ & 0,0475 \\
\hline 4 & 0,4009 & 0,1280 & 0,0863 & 0,2795 & 0,0624 & $-0,0082$ & 0,0464 & 0,0045 & 0,0169 \\
\hline 5 & 0,3775 & 0,1047 & 0,1052 & 0,2805 & 0,0570 & $-0,0408$ & 0,0607 & 0,0223 & 0,0087 \\
\hline
\end{tabular}

Tablo 2'de şirketlerin olay penceresi içerisindeki günler için anormal getirilerinin toplamını ifade eden kümülatif anormal getiriler gösterilmiștir. Kümülatif anormal getiriler, olay penceresi içerisinde, gerçekleşen olayın getiriler üzerindeki birikimli etkisini göstermektedir.

Çalışma kapsamına dahil edilen 9 şirketin 8 'inde olay penceresi içerisinde pozitif kümülatif anormal getiri değerleri gözlenmektedir. IZTAR firmasında ise olay penceresindeki olay gününe kadar gerçekleşen kümülatif anormal getiriler pozitif olmasına karşın, olay penceresinin geneline bakıldığında kümülatif 
anormal getirilerin negatife döndügü görülmektedir. Şirketlere ait kümülatif anormal getirilerin olay penceresindeki seyri Şekil 1'de gösterilmiştir.

Şekil 1. Şirketlerin Kümülatif Anormal Getirileri $\left(\mathrm{CAR}_{\mathrm{t}}\right)$

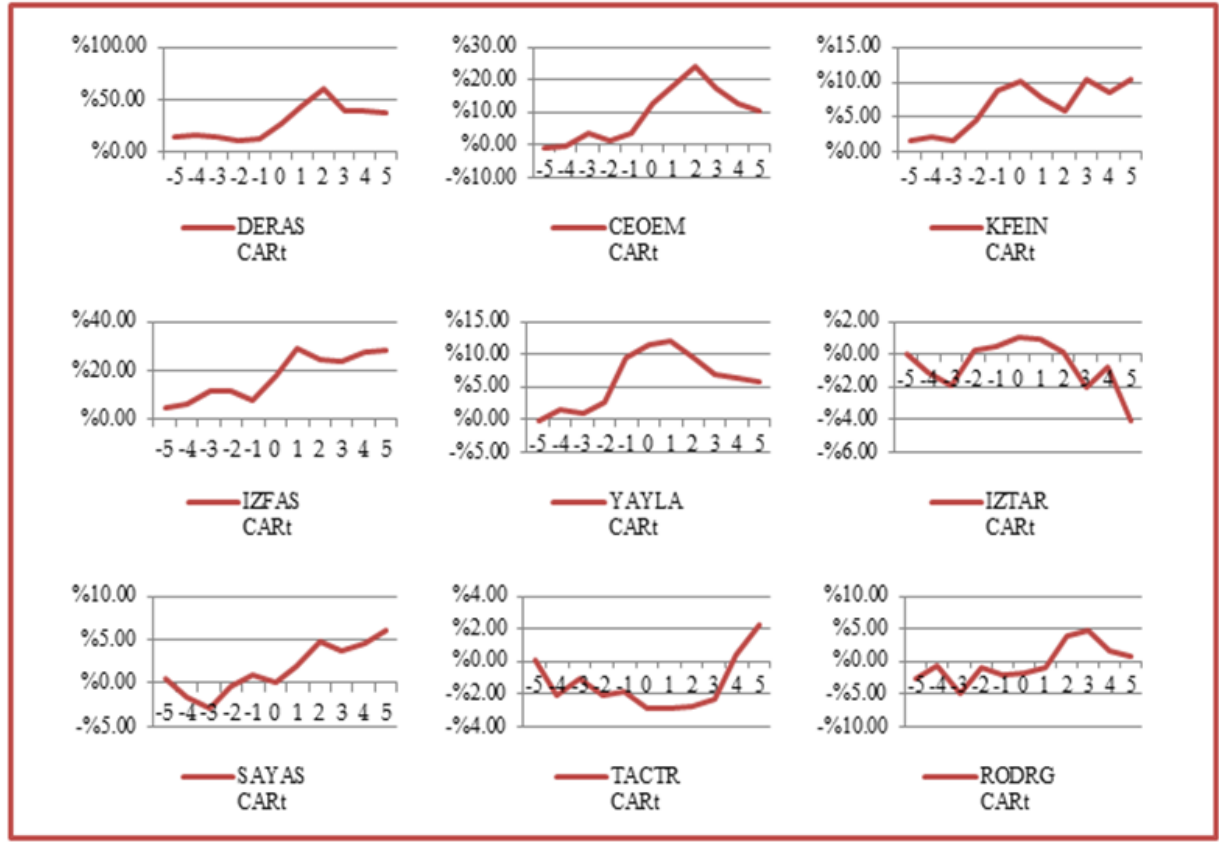

Tablo 3'de sermaye artırımı yoluyla satışa hazır bekletilen pay satışını gerçekleştiren firmaların hesaplanan kümülatif anormal getiri (CAR) değerlerinin istatiksel olarak anlamlılığı gösterilmiştir.

Tablo 3. Şirketlerin Kümülatif Anormal Getirilerinin $\left(\mathrm{CAR}_{\mathrm{t}}\right)$ İstatistiksel Anlamlılığı

\begin{tabular}{|c|c|c|}
\hline Şirket & t-istatistiği & p değeri (sig.) \\
\hline DERAS & $5,801^{*}$ & 0,000 \\
\hline CEOEM & $3,684^{*}$ & 0,004 \\
\hline KFEIN & $6,101^{*}$ & 0,000 \\
\hline IZFAS & $6,128^{*}$ & 0,000 \\
\hline YAYLA & $4,626^{*}$ & 0,001 \\
\hline IZTAR & $-1,384$ & 0,196 \\
\hline SAYAS & $1,873^{* * *}$ & 0,091 \\
\hline TACTR & $-2,755^{* *}$ & 0,020 \\
\hline RODRG & $-0,256$ & 0,803 \\
\hline \multicolumn{2}{|c|}{ Not: * \%1,**\%5,***10 anlaml11ık düzeyini göstermektedir. }
\end{tabular}

Buna göre, DERAS, CEOEM, KFEIN, IZFAS ve YAYLA firmalarında $\% 1$ anlamlıl1k düzeyinde istatiksel olarak anlamlı getiriler elde edilmiştir. Ayrıca bu firmalara ait getiriler incelendiğinde olay penceresinde pozitif CAR gerçekleştiği görülmektedir. TACTR ve SAYAS firmalarında ise sırasıyla $\% 5$ ve $\% 10$ anlamlılık düzeyinde istatiksel olarak anlamlı getiriler elde edilebildiğ anlaşılmaktadır. Bununla birlikte IZTAR ve RODRG firmalarından elde edilen kümülatif anormal getiriler istatiksel olarak anlamlı değildir. 
Tablo 4. Olay Penceresinde Ortalama Anormal Getiriler $\left(A A R_{t}\right)$ ve Kümülatif Ortalama Anormal Getiriler $\left(\mathrm{CAAR}_{\mathrm{t}}\right)$

\begin{tabular}{|c|c|c|c|c|c|c|}
\hline \multirow{2}{*}{$\begin{array}{c}\text { Olay } \\
\text { Penceresi }\end{array}$} & \multicolumn{2}{|c|}{$\mathbf{A R}_{\mathbf{t}}$} & \multicolumn{2}{|c|}{$\mathbf{C A R}_{\mathbf{t}}$} & \multirow{2}{*}{$\mathbf{A A R}_{\mathbf{t}}$} & \multirow{2}{*}{$\mathbf{C A A R}_{\mathbf{t}}$} \\
\cline { 2 - 6 } & $\mathbf{t}$-istatistiği & $\mathbf{p}$ değeri (sig.) & $\mathbf{t}$-istatistiği & $\mathbf{p ~ d e g ̆ e r i ~ ( s i g . ) ~}$ & & \\
\hline-5 & 1,139 & 0,288 & 1,139 & 0,288 & 0,0187 & 0,0187 \\
\hline-4 & 0,806 & 0,443 & 1,166 & 0,277 & 0,0054 & 0,0240 \\
\hline-3 & 0,039 & 0,970 & 1,098 & 0,304 & 0,0004 & 0,0244 \\
\hline-2 & 0,629 & 0,547 & $1,869^{* * *}$ & 0,099 & 0,0060 & 0,0304 \\
\hline-1 & 1,452 & 0,185 & $2,441^{* *}$ & 0,040 & 0,0143 & 0,0446 \\
\hline 0 & $2,113^{* * *}$ & 0,068 & $2,504^{* *}$ & 0,037 & 0,0388 & 0,0835 \\
\hline 1 & 1,805 & 0,109 & $2,333^{* *}$ & 0,048 & 0,0388 & 0,1223 \\
\hline 2 & 1,092 & 0,307 & $2,196^{* * *}$ & 0,059 & 0,0238 & 0,1461 \\
\hline 3 & $-1,301$ & 0,229 & $2,523^{* *}$ & 0,036 & $-0,0335$ & 0,1127 \\
\hline 4 & 0,029 & 0,978 & $2,441^{* *}$ & 0,041 & 0,0003 & 0,1130 \\
\hline 5 & $-0,712$ & 0,497 & $2,403^{* *}$ & 0,043 & $-0,0045$ & 0,1084 \\
\hline
\end{tabular}

Not: * \%1, ** \%5, ***\%10 anlaml1lık düzeyini göstermektedir.

Tablo 4'de olay penceresindeki ortalama anormal getiriler ve kümülatif ortalama anormal getirilere ilişkin bilgiler yer almaktadır. Ortalama anormal getiriler olay penceresindeki her bir gün için oluşan anormal getirilerin ortalamasını göstermektedir. Ortalama anormal getiri hesaplanmasındaki amaç, incelenen olay penceresindeki gün için etkisi ortaya konulmak istenen olay haricindeki firmaya özgü gelişmelerin etkisinin sınırlandırılmak istenmesidir.

Tablo 4 incelendiğinde, olay penceresi içerisinde sadece olay günüde $(\mathrm{t}=0)$ istatiksel olarak anlamlı anormal getiri elde edildiği görülmektedir. Bununla birlikte, olay tarihindeki ortalama anormal getiri ve kümülatif ortalama anormal getiri pozitif olarak gerçeklemiştir. Çalışmanın olay penceresinde yer alan diğer günler incelediğinde; olay gününü takip eden birinci ve ikinci günde sirasıyla $\% 3,88$ ve $\% 2,38$ pozitif ortalama anormal getiri elde edilmesine rağmen bu getirilerin istatiksel olarak anlamlı olmadığ görülmektedir.

Kümülatif anormal getiriler incelendiğinde; olay penceresindeki ( $\mathrm{t}=-1$, $\mathrm{t}=0, \mathrm{t}=1, \mathrm{t}=3, \mathrm{t}=4, \mathrm{t}=5)$ günlerinde $\% 5$ anlamlılık düzeyinde istatiksel olarak anlamlı getirilerin elde edilebildiği anlaşılmaktadır. Söz konusu günlerden $t=-1$, $\mathrm{t}=2$ aralığında ve $\mathrm{t}=4$ gününde gerçekleşen getiriler pozitif, $\mathrm{t}=3$ ve $\mathrm{t}=5$ günlerindeki getirilerin ise negatif olduğu görülmektedir. Ayrıca olay penceresinden $\mathrm{t}=-2$ ve $\mathrm{t}=2$ günlerinde $\% 10$ anlamlılık düzeyinde istatiksel olarak anlamlı pozitif kümülatif anormal getiri elde edilebilmiştir.

Şekil 2. Kümülatif Ortalama Anormal Getirilerin Olay Gününe Duyarlılı̆ğ $\left(\mathrm{CAAR}_{\mathrm{t}}\right)$

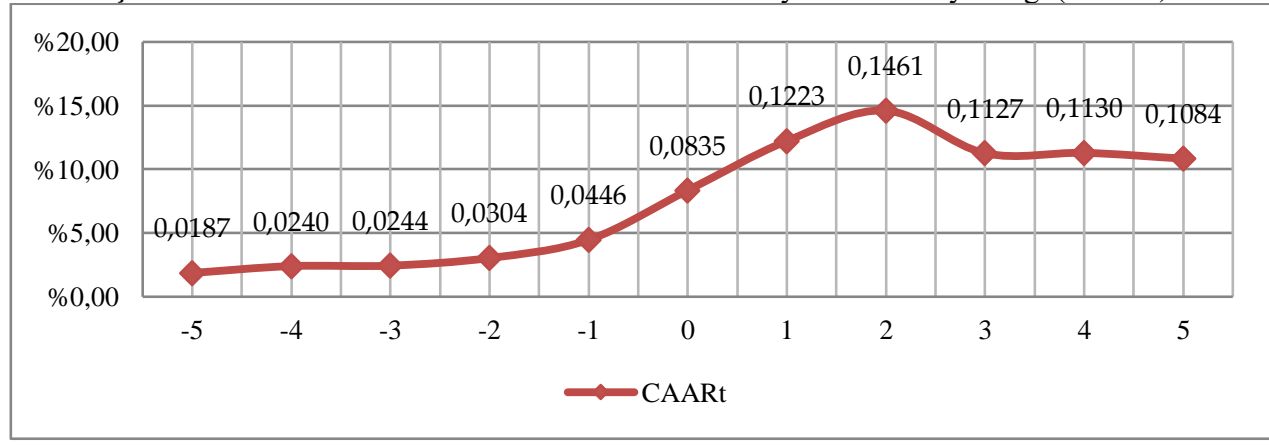


Şekil 2'de ortalama anormal getirilerin kümülatif toplamlarının olay penceresi içerisindeki seyri yer almaktadır. Grafik 2 incelendiğinde, olay günü ve sonrasındaki iki gün için pozitif bir seyir olduğu görülmektedir. Ayrıca, olay günü $\mathrm{t}=0$ ve sonraki gün $\mathrm{t}=1$ gerçekleşen pozitif anormal getiriler incelenen olay penceresindeki en yüksek getirilere işaret etmektedir. Satışa hazır bekletilen payların satışından sonrasındaki üçüncü günde ise, getirilerde bir azalış meydana geldiği ve sonrasında yatay bir seyir izlediği görülmektedir.

\section{SONUÇ}

Küreselleşme süreci ile birlikte uluslararası pazarlara erişim imkanı ve artan rekabet koşulları şirketlerin sermayeye olan talebini artırmaktadır. Büyüme ve gelişme sürecindeki şirketlerin sermaye ihtiyacının karşılanmasında farklı seçenekler bulunmaktadır. Ne var ki halka kapalı şirketler için sermaye piyasalarından elde edebilecekleri kaynaklar sınırlı kalmaktadır. Bu doğrultuda şirketlerin paylarını halka arz ederek bireysel ve kurumsal yatırımcılardan kaynak temin edebilmesi önemli bir alternatif olarak öne çıkmaktadır. Kurumsal yapının güçlendirilmesi, firma itibarına katkısı, sektördeki rekabet gücünün artırılması, yatırımların finansmanı ve kaynaklara daha uygun koşullar ile erişim imkanı vb. faktörler de şirketleri paylarını halka arz etmeye yöneltmektedir.

Paylarını halka arz etmek suretiyle sermaye piyasalarından kaynak sağlamak isteyen şirketlerin gerçekleştirecekleri pay ihracına ilişkin usul ve esaslar SPKn çerçevesinde Pay Tebliği ile düzenlenmiştir. Pay Tebliğinde belirli koşulların oluşması dahilinde şirketlerin kullanabilecekleri bir hak olan satışa hazır bekletilen paylar yer almaktadır. Halka açılma sonrasında satışa hazır bekletilen payların satılması bir yandan şirkete halka arz edilecek payların nominal değerinin $\% 25$ 'ine tekabül eden payların o anki geçerli borsa fiyatından satışıyla ilave kaynak sağlamakta, diğer yandan satış sonucu ilave payların yatırıcılarla buluşması halka açıklık oranını arttırmakta ve payların işlem hacmi ve derinliğine olumlu katkı sunmaktadır.

Bu çalışmada sermaye artırımı yoluyla satışa hazır bekletilen pay satışının hisse senedi getirileri üzerine etkileri incelenmiştir. Olay etüdü yönteminin kullanıldığı çalışmada 2013-2020 yılları arasındaki satışa hazır bekletilen payların satışı çalışma kapsamını oluşturmaktadır. Elde edilen bulgulara göre; satışa hazır bekletilen pay satışının yapıldığı tarihte $(\mathrm{t}=0)$ istatiksel olarak anlamlı ve pozitif getiri, olay tarihinden sonra birinci $(t=1)$ ve ikinci $(t=2)$ günlerde de pozitif ancak istatiksel olarak anlamsız getirilerin elde edildiği görülmektedir. Çalışma sonuçları genel olarak incelendiğinde, olay penceresi içerisinde olay günü ve sonrasında pozitif anormal getirilerin varlığı BIST pay piyasasının yarı güçlü formda etkin olmadığının bir göstergesidir. Bu doğrultuda piyasanın yarı güçlü formda etkin olduğunu kabul eden $\mathrm{H}_{0}$ hipotezi reddedilerek $\mathrm{H}_{1}$ hipotezi kabul edilmiştir.

Yatırımcılar açısından ele alındığında, sermaye artırımı yoluyla satışa hazır bekletilen payların satışının hisse senedi getirilerini olumlu yönde etkilediği fakat bu uygulamayı takip ederek yatırımcıların büyük miktarlarda ve uzun süreli 
pozitif getiriler elde edemeyeceği, ancak kısa dönemli pozitif anormal getiri elde edebilmenin mümkün olduğu söylenebilir.

Çalışma, gelecek yıllarda ilk halka arz sonrasında sermaye artırımı yoluyla satışa hazır paylarını satan şirketlerin sayılarının artmasıyla beraber farklı olay pencereleri için aynı yöntemle ve/veya farklı yöntemlerle tekrarlanarak geliştirilmeye açıktır.

\section{KAYNAKÇA}

Adaoğlu, C. (2006). Market Reaction to "Unsweetened" and "Sweetened" Rights Offerings in an Emerging European Stock Market. Journal of Multinational Financial Management, 16(3), 249-268. Retrieved from https://papers.ssrn.com/

Alhashel, B. S. (2016) Rights Offering Announcements and the Efficiency of the Kuwaiti Market. Applied Economics Letters, 23(17), 1-5. DOI: 10.1080/13504851.2016.1142650

Başdaş, U., \& Oran, A. (2014). Event studies in Turkey. Borsa Istanbul Review, 14(3), 167-188. DOI: $10.1016 /$ j.bir.2014.03.003

Bashir, A. (2013). Impact of Right Issues Announcement on Shareholders Wealth: Case Study of Pakistani Listed Companies. International Journal of Contemporary Business Studies, 4(3), 6-12.

Bianco, S. D., Bruno, R. L., \& Signorelli, M. (2015). The Joint Impact of Labour Policies and the "Great Recession" on Unemployment in Europe. Economic Systems, 39(1), 3-26. DOI: 10.1016/j.ecosys.2014.06.002

BİST, Borsa İstanbul. (2020). https://www.borsaistanbul.com/sirketler/halka-arz-ve-borsada-islemgorme/pay-piyasasi/halka-arz/halka-arzin-faydalari-halka-arza-hazirlik-ve-halka-arzsurecleri/halka-arz-ve-satis-yontemleri/halka-arz-yontemleri, Erişim: 10.06.2020

Chen, C., \& Chen, X. (2007). The Information Content of Rights Offerings in China. Research in International Business and Finance, 21, 414-427. DOI: 10.1016/j.ribaf.2006.12.006

Çırak, R. (2018). Şirket Değerleme Yöntemleri. Ankara: Seçkin Yayıncılık.

Ercan, M. K., Öztürk, M. B., Küçükkaplan, İ., Başcı, E. S., \& Demirgüneş, K. (2007). Halka Açık Firmaların Beta Katsayılarının Regresyon Modeli İle Tespiti ve Halka Açık Olmayan Firmalara Yönelik Uygulanabilirliği. Dokuz Eylül Üniversitesi İktisadi ve İdari Bilimler Fakültesi Dergisi, 22(2), 295-324.

Erol, A. F., \& Aytekin, S. (2018). Borsa İstanbul Pay Piyasası Şirketlerinin Bedelsiz Sermaye Artırımı Duyurularının Hisse Senedi Getirileri Üzerindeki Etkisinin Değerlendirilmesi. Mehmet Akif Ersoy Üniversitesi İktisadi ve İdari Bilimler Fakültesi Dergisi, 5(3), 898912. DOI: 10.30798/makuiibf.439219

Kaderli, Y. (2007). Yapılan İhracat Bağlantılarının İlgili Firmaların Hisse Senedi Getirileri Üzerindeki Etkisinin Olay Etüdü İle İncelenmesi: İstanbul Menkul Kıymetler Borsası'ndaki Bazı Firmalar Üzerine Bir Uygulama. MUFAD Muhasebe ve Finansman Dergisi, Sayı 36, Ekim, 144-154.

KAP, Kamuyu Aydınlatma Platformu (2020). https://www.kap.org.tr/tr/ Erişim: 10.06.2020

Karan, M. B. (2013). Yatırım Analizi ve Portföy Yönetimi (4. bs.). Ankara: Gazi Kitabevi.

Kartal, M. K. (2017). Sermaye yapısı. A. Gündoğdu (Ed.), Finansal Yönetim Temel Teoriler ve Açıklamalı Örnekler içinde (s.423-448). İstanbul: Seçkin Yayıncılık.

Kederli, Y., \& Başkaya, H. (2017). Halka Açık Firmalarda Sermaye Arttırımı Duyurularının Hisse Senedi Üzerindeki Etkisinin Ölçülmesi: Borsa İstanbul'da Bir Uygulama. [Özel Say1]. Aydın İktisat Fakültesi Dergisi, 2(1), 28-42.

Kendirli, S., \& Elmal1, M. E. (2016). The Effects of Right Offering Announcements on Returns of Shares of Deposit Banks Traded in Istanbul Stock-Exchange. Journal of Economic Development, Environment and People, 5(1), 74-82.

Köseoğlu, S. D. (2010). 1997-2010 Dönemi Türk Bankacılık Sektörü Risk Analizi. Niğde Üniversitesi İ.İ.B.F Dergisi, 3(2), 119-134. 
Küçüksille, M., \& Mizrahi, R. (2015). Bedelli Sermaye Artırımı Duyurularının Halka Açık İşletmelerin Hisse Senedi Performanslarına Etkisi: Borsa İstanbul'da Bir Araştırma. KMU Sosyal ve Ekonomik Araştırmalar Dergisi, 17(29), 63-69.

Ma, J., Pagan, J. A., \& Chu, Y. (2009). Abnormal Returns to Mergers and Acquisitions in Ten Asian Stock Markets. International Journal of Business, 14(3), 235-250.

Mahmood, S., Mirza, H. H. \& Mushtaq N. (2014). Market Reaction to the Rights Issue Announcements: Evidence from an Emerging Market. Vidyabharati International Interdisciplinary Research Journal, 3(2), 91-111.

Mishra, A. K. (2005). An Empirical Analysis of Market Reaction Around the Bonus Issues in India. (Indian Institute of Management Working Paper No. 2005-10). https://ssrn.com/abstract=733043

Ogada, A., \& Kalunda, E. (2017). Impact of Rights Issue on Share Returns of Firms Listed on the Nairobi Securities Exchange, Kenya. IOSR Journal of Business and Management, 19(8), $54-62$.

Omağ, A. (2015). Finansal Kaldıraç Derecesi ve Seçilmiş Sektörlere Yönelik Bir Uygulama. Maliye Finans Yazıları, 103, 205-218.

Otieno, O. D. \& Ochieng, D. E. (2015). The effects of Rights Issue Announcements on Stock Returns for Firms Listed at the Nairobi Securities Exchange. International Journal of Education and Research, 3(9), 411-426.

Owen S., \& Suchard, J. (2008). The Pricing and Impact of Rights Issues of Equity in Australia. Applied Financial Economics, 18(14), 1147-1160. DOI: 10.1080/09603100701537706

Özer, G., \& Yücel, R. (2001). İMKB'de Hisse Senedi İhraç Tarihi Etrafındaki Anormal Fiyat Hareketleri. Active, Bankacilık ve Finans Dergisi, 3(16), 60-68.

Ramesh, S., \& Rajumesh, S. (2014). Information Content of Right Issue Announcements: A Study of Listed Companies in Colombo Stock Exchange of Sri Lanka. Research Journal of Finance and Accounting, 5(5), 154-162.

Rohit, B., Pinto, P. \& Bolar, S. (2016). Impact of Stock Splits and Rights Issue Announcements on Market Price: Evidence from India. Drishtikon: A Management Journal, 7(2), 1-16.

SPK, Sermaye Piyasası Kurulu (2013). Pay Tebliği (VII-128.1). https://www.resmigazete.gov.tr/eskiler/2013/06/20130622-8.htm, Erişim: 10.06.2020

Suresha, B., \& Chandrashekara, B. (2016). Market Efficiency Around Bonus, Stock Split and Rights Issue Announcement-Evidence from India. Journal of Economics and Sustainable Development, 7(11), 71-79.

Yaşar, S. (2006). Firma Finansmanında Hisse Senedi Piyasalarının Rolü: Türkiye Örneği (Yayın No: 200). Ankara: Sermaye Piyasası Kurulu Yayınları.

Yiğit, F. (2016). Sermaye Yapısı ve Sermaye Yapısı Teorileri. Ankara: Nobel Yayıncılık.

\section{SUMMARY}

Along with the globalization process, access to international markets and increasing competition conditions increase companies' demand for capital. There are different options to meet the capital needs of the companies in the growth and development process. However, the resources available for non-public companies to obtain from the capital markets are limited. In this regard, it is an important alternative for companies to offer their shares to the public and obtain resources from individual and institutional investors.

The procedures and principles regarding the issuance of shares to be realized by companies wishing to provide resources from the capital markets by offering their shares to the public are regulated by the Share Communique within the framework of the CMB. According to the Share Communique (Article 9), if the market price of the partnerships whose shares other than additional sales will be offered to the public for the first time to be calculated on the basis of public 
offering price is less than 40 million TL, before the approval of the offering circular regarding the public offering, the shares which constitute $25 \%$ of the shares to be offered according to their nominal value are kept ready for sale by restricting the existing partners' right to buy new shares. It is stated in paragraph 1 of Article 10 that the sale of the shares kept ready for sales within the scope of the Communiqué will be performed by the intermediary institution. In addition, it has been announced that the sale of shares kept ready for sale can be carried out in one or more times within one year (based on the date of publication) from the date of publication of the offering circular on the Public Disclosure Platform (PDP).

This study aims to investigate the effects of BIST Equity Market companies' share sales, which are kept ready for sale through a capital increase, on equity returns. Accordingly, companies that issued their shares kept ready for sale in the 2013-2020 period were included in the analysis. In the said period, due to reasons such as the size of the public offering being higher than the amounts specified in the share notification and the shares kept ready for sale not being sold in the specified period, 38 of 51 companies that offered their shares to the public could not realize the sale of their shares kept ready for sale. While the remaining 13 companies were included in the study, 4 companies that did not have compatible data according to 5 days before and 5 days $(-/+5)$ after used as the event window were excluded from the analysis. Accordingly, the analysis was continued with a total of 9 companies whose data could be accessed, and data compatible with the method could be provided.

An event study method was adopted to examine the effects of BIST Equity Market companies' share sales, which are kept ready for sale, on equity returns. Within the scope of the study, the sale date of the shares kept ready for sale was determined as the event day. As the event window, 5 days before and after the event day $(-/+5)$ were examined. Logarithmic returns of the daily closing prices of the shares of the companies included in the analysis in this range were calculated. The Capital Asset Pricing Model, which is one of the economic models, was used to calculate the expected returns of the equities.

According to the findings obtained, it was observed that statistically significant and positive returns were obtained on the date of sale of shares kept ready for sale $(\mathrm{t}=0)$, and positive but statistically insignificant returns were obtained on the first $(t=1)$ and second $(t=2)$ days after the event date. When the results of the study are analyzed in general, the presence of positive abnormal returns on and after the event within the event window is an indication that the BIST Equity Market is not a semi-strong form efficient market. Accordingly, the $\mathrm{H}_{0}$ hypothesis, which accepted that the market was semi-strong form efficient, was rejected, and $\mathrm{H}_{1}$ was accepted.

As a result, it was determined that the sale of shares kept ready for sale through capital increase positively affected the equity returns, but following this application, it would not be possible for investors to obtain large amounts of long term positive returns, but it would be possible to obtain short term positive abnormal returns. 
The study is open to development by repeating the same method and/or different methods for different event windows, with the increase in the number of companies selling their shares kept ready for sale through capital increase after the initial public offering. 